International Journal of Scholarly Papers for Media and Communications

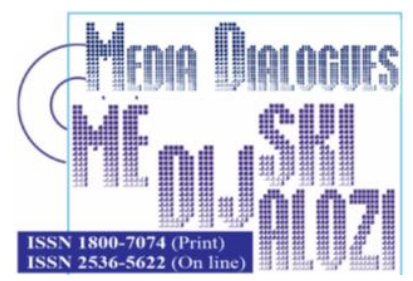

Simovic, O., Raicevic, M. (2020), „How Social Media and Social Networks Changed the Way of Doing Business in the Tourism Industry", Media Dialogues / Medijski dijalozi, Vol. 14, No. 2, pp. 21-29.

\title{
How Social Media and Social Networks Changed the Way of Doing Business in the Tourism Industry
}

\section{SIMOVIC OLIVERA}

University of Montenegro, Faculty of Tourism and Hotel Management, Kotor, Montenegro

\section{RAICEVIC MILICA}

Faculty of Economics and Business, Mediterranean University, Podgorica, Montenegro

\begin{tabular}{|c|c|}
\hline $\boldsymbol{A} \boldsymbol{R} \boldsymbol{T} \boldsymbol{I} \boldsymbol{C L} \boldsymbol{E}$ & Received: November 07, 2021 / Revised from: December 07, 2021 \\
$\boldsymbol{I} \boldsymbol{N} \boldsymbol{F} \boldsymbol{O}$ & Accepted: January 08, 2021 / Available online: October 15, 2020 \\
\hline DOI & doi.org/10.14254/1800-7074/13-4/2 \\
\hline
\end{tabular}

\section{ABSTRACT}

Considering the fact that tourism is the fastest growing industry in the world, constant changes and innovations are inevitable. Using new and innovative distribution and sales channels such as social networks, is one of those changes. Thanks to social media, the revolution of the Internet and its influence on the industry of tourism has reached a new stage. The importance of social media such as Facebook, Twitter, Instagram and others, is inevitable when talking about the promotion of tou- 
rist destinations, their services and products. This paper's main goal is to explore how social media and social networks influence people's decision making when choosing a tourist destination for their next visit. It's undeniable that they are a powerful tool nowadays, since the Internet has become an important part of everyone's lives.

KEYWORDS: Social media, Social networks, Communications, Tourism industry.

\section{INTRODUCTION}

Simply put, social networks are online platforms, used by people to build some kind of social relations with people of similar interests and it allows them to communicate and share information on the internet (Kirtis and Karahan, F., 2011). The development of technology has had the biggest influence on the development of social networks, but the fact that they are easy to use and free, has attracted many of their users. Besides being the reason many people started using them, the fact that social networks are free, makes them a good way companies in the tourism industry could spend less money on marketing, especially when it comes to advertising their products and services (Pantano et al., 2010, pp. 609-614).

One of the biggest changes that the Internet and social networks have brought to the tourism industry can be seen in the wider availability of information that possible buyers can find at any time, just by reaching out for their laptop or smartphone and typing a few words into their web browser (Brown, 2017). Everything they wanted to know about a tourist destination, how to get there, where to stay, what to do, today all those information can easily be found on the Internet. It goes wider than the basic info, photos, or facts about a place, to other people's experiences, comments, things that might affect the buyer's choices of a destination as well.

This has resulted in big changes when it comes to buyers' behaviour, and so today they exchange information and experiences between themselves. The fact that the Internet has made the industry much more transparent, through social media such as the Tripadvisor, whose name itself says that its content is supposed to advise you on your trip; that offers you an insight on other people's experiences on their travels and why you should, or should not choose a certain destination/hotel/restaurant etc. makes it obligatory for any company in the tourism industry to maintain their service on a certain level if they want their customers to be satisfied with them, and perhaps rate them or write a comment about them on the Internet (https://www.theguardian. com/news/2018/aug/17/how-tripadvisor-changed-travel). 


\section{THE ROLE AND IMPORTANCE OF SOCIAL MEDIA IN THE TOURISM INDUSTRY}

Considering the particularity of tourism products and services, that they are intangible, can not be stored, and demand a high level of interpersonal relationships (Kietzmann et al., 2011) the changes that the Internet and social media in particular have brought into the tourism industry actually are of great importance for the development and efficacy of the industry. Also, it is considered that the old fashioned ways of promoting and advertising through presentations and flyers are long gone, and if you do not exist on the Internet, it is as if you do not exist at all (Miller, 2017).

Of course the influence of the social media on people's travel decisions begins way before they even start considering booking a holiday. Just ask yourself how many times a day do you reach for your phone in your free time to check your social media profiles. Now imagine a millenial scrolling their facebook or instagram profile, and coming across an ad, a photo of their friend, or of that travel page or blogger they follow. Being exposed to such content, perfectly posed photos on a beach somewhere in Portugal, or having a dinner overlooking the Duomo Cathedral in Milan, it has been scientifically proven that it affects people (millennials the most), and this syndrome is now known as the FOMO - Fear of missing out (Sapadin, 2015).

As the name itself says, fear of missing out represents a sort of anxiety from what we might be missing out on if we do not see/do/try something we saw someone else enjoying in, to be more precise, on someone's instagram or facebook profile (http://psychcentral.com/blog/archives/2015/10/12/fear-of-missing-out/). It goes like that for travel as well. We can not say that past generations have not suffered from this form of social anxiety as well, but it is undeniable that FOMO has intensified in the last few years, with social media being the main reason for that. The Millennials (Price,W. 2016), being the generation of people born between the 1981 and 2001, is probably the age group that has been affected the most by the development of social media and its influence on our everyday life. When you think about it, we should not be surprised by this, considering the number and variety of content with other people's experiences in the places they visited, we come across on the Internet scrolling through social networks such as Facebook or Instagram. This phenomenon has become a component of millennials' everyday life, but of all others who spend a significant amount of time on social networks, too. It is no surprised that some people name it the modern plague of the 20s (https://www.ruschellekhanna. com/blog/2018/2/2/ overcoming-fomo-in-your-twenties).

Then it is no surprise that according to some research $87 \%$ of the Millennials are inspired to travel and choose a certain tourism destination by what they saw on Facebook (Price, 2016). Things posted by friends or other followers who might have just come back from a holiday, inspire users to start thinking about a visit to some tourist destination themselves, even if they were not even considering it to that point. According to a research done by AdWeek (https://www.adweek.com/socialtimes/ 
social-media-and-travel-go-hand-in-hand-infographic /625230/), 52\% of Facebook users dream about travelling while on line, although there was no sign of having the need for travel beforehand. It is an example of how FOMO works and has a strong influence on young individuals; another research reveals that $69 \%$ of Millennials have expressed remorse for not travelling somewhere last minute (http://www. internet marketinginc.com/blog/millennial-travel-trends/).

The Olapic website whose content reflects on subject regarding the tourism industry, travels, marketing, social media and their influence, recently published an article talking about how social networks affect individuals in a way to wake up a desire for travelling in them (Brown, 2017). So far it has been proven that social networks have in fact a strong influence even on the phase that precedes the acknowledgment of the existence of a need for travelling in a person. Partially, this is due to the fact that the Internet is filled with social networks and platforms that, among other things, offer a greater variety of information than brochures and old-fashioned guide books used to.

Even the way in which people, the younger generations especially, plan their travels has changed in the last few years; and the phase of finding information made a lot easier but also deepened, thanks to social networks (Fotis et al., 2012). Numerous web sites give people the opportunity to post their experiences, comments, critiques and praises about every segment of their travel-starting from buying the ticket and choosing an airline, through finding a way to transfer from the airport to the destination, to some details in the hotel or private accommodation, and finally about tourist attractions in the destination, what is worth visiting and the overall experience. Therefore, it is not surprising that according to a research from 2016, $59 \%$ of decisions made to go on a trip, were made under the influence of comments read on web sites such as TripAdvisor. (D'Astolfo and Gasdia, 2016).

Another research says that $88 \%$ of the respondents younger than 34 were inspired by the content saw on Facebook to choose a certain destination (Text100, 2014).

After realizing that the need for travel in fact exists, the next step is looking for additional information on the destination (Perkins, 2014). In that sense, photos, videos and comments from other visitor can greatly influence the customer's decision. For example, a destination never visited before by the potential customer, it is quite probable that content posted by friends or people on their following list will have a stimulating effect on his/hers decision. Shared photos and videos have a positive influence on reducing risk perception, and later on on the very process of making a decision. Research done by Pricewaterhouse Coopers has shown that $65 \%$ of Internet's European users think if the web as of the primary source of information when planning a trip (Labbe, 2011, pp. 26-27).

After identifying alternatives, visitors compare them with the aim of making the best choice. 
This phase is followed by the one in which the customer makes a decision on buying a certain tourist product or service. This partially depends on the tourist's motivation, but also on the influence he was under in the previous phases.

The influence of social networks does not stop once the customer sets off on a trip, but it continues throughout his/hers whole journey. Airports, hotel, restaurantsthey will all allow them to connect to the Internet for free, and continue the sharing of content regarding the destination and all of its components (Minazzi, 2015, p. 59).

Although visitors use more devices during the different stages of planning a trip, the use of mobile phones is dominant during their travels. They allow them to be informed at all times about the weather, offers in restaurant, activities in the destination etc. During their stay in the destination, the social networks' role triples: it allows them to look for information regarding everything they need during their stay, allows them to communicate with their friends and family, and share experiences from their travels in real time (Saeed et al, 2010, pp. 502-517).

It is also important to mention that if a tourist has a habit of using social networks while at home, and used them while planning their journey, it is most likely that he/she will continue to use them during the travel as well.

The importance of social networks does not decrease even when the customer comes back from the journey. A report by the ComScore says that $45 \%$ of tourists post different content and comments regarding their travels on their social networks right after returning from a trip (ComScore, 2013).

They turn to TripAdvisor for rating the experiences they had, and express satisfaction or even dissatisfaction with the services used throughout their journey. Sometimes tourist are additionally stimulated to leave positive feedback by receiving thank you letters sent by service providers even a few days after the end of their trip. Whether it is sharing photos and videos about the wonderful trip they just returned from, or writing complaints on certain products or services they received during that trip, either way, tourists turn to social networks. This is a great opportunity for some companies and service providers to develop their users' loyalty, and create a long term mutually useful relationship (Minazzi, 2015, p. 60).

Based on everything mentioned so far, we can see that the development of technology, and especially social networks has had a great influence on the industry of tourism, and especially on the elements of the marketing mix.

\section{HOW TECHNOLOGY IS CHANGING THE TOURISM INDUSTRY}

Technology has been changing the elements of tourism services and delivery mechanisms that are far from the selling process. On the one hand, social networks have become an inevitable segment in planning a trip, while on the other hand, they have also become a new channel of distribution and a great source of information. 
Big changes have been made in the area of collecting information and data, and the social networks' influence in it is constantly getting bigger; which is why it is important to adapt the elements of the marketing mix to new trends in doing business.

As the first element of the marketing mix - the "product" is quite particular in tourism, since as we mentioned before, it can not be stored, its place of origin is detached from the place where it is being used, and it is intangible (Friebe and Campbell, 2010). A lot of thought has to be put into the tourist product in order for it to successfully attract potential buyers, and information play an important role in that process. Social networks are an inexhaustible source of information which is why companies ought to adjust their products to new trends, more precisely by implementing social media in "serving" it to their customers, with the help of comments, photos, sounds and videos.

Subjects in the tourism industry have the possibility to be in direct contact with their potential customers, and vice versa. While forming the prices of their products and services, the availability of information on their competitors influences their place on the market. Thanks to social networks it is possible to inform customers about low cost and last minute travel arrangements, create a base of loyal customers and a reward programme for them and by doing that, reduce the number of intermediaries in the process. Being one of the most influential channels of distribution, social networks' importance depends on their customers since they are the ones giving feedback and recommending certain products and services.

Through this analysis we will be able to come to a conclusion on how this phenomenon of social networks can be incorporated into promoting a tourist destination successfully with visible results in a relatively short period of time.

We can't be talking about social networks without mentioning the "influencers"the expression marking a person with a great number of friends on Facebook or followers on their Instagram account, and therefore in a position that allows them to reach out to a great number of people and with what they post, influence them in a way (https:// dictionary.cambridge.org/dictionary/ english/influencer).

The role of influencers has been recognized as important since the content they post really does affect their followers' choices when buying something, as well as their behaviour-therefore also affecting their decisions when it comes to choosing a tourist destination. Nowadays, they are being hired by big companies and brands, and especially by those in the tourism industry, to post and write positive content and post photos about certain travel experiences, hotels they stayed in, restaurants in which they ate, etc. hoping to be the reason many more decide to choose those exact places on their travels.

To this point, it is safe to conclude that education, existing experience and gaining new knowledge and skills on social networks is an important element for tourist 
destination's and its business further development and improvement of its positioning on the market.

When it comes to Montenegro, the number of its residents that use social - is constantly growing. According to the website Internet world stats, in the year 2017. Montenegro had the biggest penetration when it comes to social networks, even though in general it had the lowest penetration on the internet in the whole region. Number of active users of social networks makes up for 56\% of the population (https:// www.internetworldstats.com/stats4.htm).

\section{CONCLUSIONS}

All things considered, we could define five main problems companies might run into when it comes to incorporating social networks in their business:

- How and why should social networks be used in tourism and for promoting a certain tourism product/service and/or destination?

- How to define goals that are trying to be achieved by implementing social networks into the process of creating an offer of a tourist destination?

- How to place a certain tourist destination's content on social network and use it for its promotion?

- What kind of content should be used for placing on social networks?

- Why is it necessary to share knowledge about what has been achieved?

As an answer to the problems, it is enough to mention once again how easy it is to reach a certain target group through social networks that allow promotion of the service or destination based on market segmentation. Through statistics it is possible to measure the effectiveness of those activities, and the influence of the information being shared. And of course, the use of social networks is free of charge. Use of social networks for business is quite different than the one for personal purpose, and from the former it is expected to strengthen the brand, find new customers and improve effectiveness. They create a two-way communication, which makes every business closer to their customers. Even though they are used to being formal, the informal setting of social networks allows them to reach potential customers in an easier way. Nonetheless, they must keep in mind that the content they post must be relevant, interesting and useful, with the main goal to attract as many potential customers. Individual tourism business who put social networks in a good use and successfully promote themselves, in a way promote the destination itself as well.

Despite its possible negative effect on individuals, even when it comes to promoting businesses in the tourism industry, its positive effects are currently prevailing, and contributing to the development of tourist destinations and everyone involved in the process of creating a tourism product/service. 


\section{REFERENCES}

Brown, R. (2017), The Impact of Social Media on Travel Inspiration, http://www. olapic.com/resources/the-impact-of-social-media-on-travel-inspirat ion_blogp1aw-f1tr-v1th-t1sm/

D'Astolfo, T., Gasdia, M., Gerstel, A. (2016), From Sharing to Booking: Exploring the role of UGC on Travel Shopping, https://www.phocuswright. com/TravelResearch/Technology-Innovation/From-Sharing-to-Booking-Exploring-theRole-of-UGC-on-Travel-Shopping

Friebe, K., Campbell, D. (2010), "Social media in the hospitality industry", Journal of Hospitality \&Tourism Research, Vol. 39, No. 1, pp. 147-169.

Fotis, J., Buhalis, D., Rossides, N. (2012), Social media use and impact during the holiday travel planning process, Springer-Verlag, str. 13-24.

Kirtis, A.K., Karahan, F. (2011), To Be or Not to Be in Social Media Arena as the Most Cost Efficient Marketing Strategy after the Global Recession, Elsevier Ltd.

Kietzmann, J.H., Hermkens, K., McCarthy, I.P., Silvestre, B.S. (2011), "Social Media? GetSerious! UnderstandingtheFunctional Building Blocksof Social Media", BusinessHorizons, ScienceDirect, Vol. 54, No. 1, pp. 241-251.

Labbe, M. (2011), "A natural partnership: Turism \& Online marketing", International Trade Forum, Vol. 2, pp. 26-27.

Miller, C.(2017), How Instagram is changing travel, https://www. google.me/amp/s /relay.nationalgeographic. com/proxy/ distribution/public/ amp/travel/travelinterests/arts-and-culture/how-instagram-is-changing-travel

Minazzi, R. (2015), Social Media Marketing in Tourism and Hospitality, Springer.

Pantano, E., Taversine, A., Viassone, M (2010), "Consumer perception of computermediated communication in a social network", Proceedings of the 4th International Conference on New Trends in Information Science and Service Science, IEEE Computer series, IEEE, Gyengju, str. 609-614.

Perkins, C. (2014), Infographic: Optimising hospitality marketinh through the five stages of travel, May 12, http://www.bighospitality.co.uk/ Business/ Infographic-Optimising-hospitality-marketing-through-the-five-stage $30 \mathrm{~s}$-oftravel?utm_source=RSS_text_news\&utm_ medium=RSS\%2Bfeed\&utm _ca mpaign= R SS\% 2BText \%2B News

Price, W. (2016), Millenial Travel Trends: A Look at the Largest Generations' Habits, https:// www. internetmarketinginc .com/blog/millennial-travel-trends/

Saeed, G., Brown, A., Knight, M., Winchester, M. (2010), "Delivery of pedestrian real-time location and routing information to mobile architectural guide", Automation in Construction, Vol. 19, No. 4, pp. 502-517.

Sapadin, L. (2015), Fear of Missing Out,12/10/2015, http://psychcentral. com/blog/ archives/2015/10/12/fear-of-missing-out/ http://psychcentral.com/blog/archives/2015/10/12/fear-of-missing-out/

Text100 (2014), Digital Indeks: Travel \& Tourism Study https://www.slideshare. net/dublanchet/text-100 
https://dictionary.cambridge.org/dictionary/english/social-network

https://www.theguardian.com/news/2018/aug/17/how-tripadvisor-changed-travel https://www.researchgate.net/post/What_are_the_key_differences_between_ tourism_and_other_service_providing_organizations

http://psychcentral.com/blog/archives/2015/10/12/fear-of-missing-out https://www.ruschellekhanna.com/blog/2018/2/2/overcoming-fomo-in-your-tw enties

https://www.adweek.com/socialtimes/social-media-and-travel-go-hand-in-handinfographic/625230

http://www.internetmarketinginc.com/blog/millennial-travel-trends

https://dictionary.cambridge.org/dictionary/english/influencer

https://www.internetworldstats.com/stats4.htm. 